\title{
Haciendas Provinciales
}

Abre la reciente Ley de Bases de Régimen Local nuevos y dilatados horizontes al desenvolvimiento de nuestras Diputaciones provinciales. Frente al criterio muy extendido de empequeñecer estas Corporaciones, limitando sus facultades y contra la oposición aún más radical, de llegar a su supresión, por considerarlas faltas de vigor y eficacia, como frutos de importación carentes de arraigo y ambiente nacionales, la Ley que comentamos ha sabido inspirarse en un espíritu más elevado y justo, reconociendo la posibilidad de obtener de las Diputaciones un rendimiento provechoso para la prosperidad nacional, ampliando su competencia, impulsando su acción y, sobre todo, ofreciénddoles medios indispensables para una labor eficiente.

Escapan al tema de este artículo las cuestiones relativas a la organización, funcionamiento y esfera de actividades de las Corporaciones provinciales, cuyo estudio, por su interés y trascendiencia, merece ser tratado con mayor extensión. Por eso hemos de limitamos al aspecto puramente económico, examinando los recursos que la nueva-Ley ofrece a las Diputaciones y las características esenciales de la ordenación de sus Haciendas.

El sistema anterior de recursos provinciales of rece serios reparos, tanto en el orden doctrinal como en el aspecto práctico de sus rendimientos y posibilidadles futuras.

La base fundamental de la economía provincial descansaba sobre la aportación forzosa municipal y. sobre un complicadio sistema de participaciones en ingresos propios del Estado y de los Ayun- 
tamientos. Sólo poseían como recurso directo y peculiar, el llamado arbitrio sobre la riqueza radicante, improcedente por antieconómico e injusto. Los demás recursos, por su propia naturaleza, no sólo eran inaceptables, sino que perjudicaban a las Diputaciones, pues constituyendo detracciones de los Presupurestos municipales y del Estado, creaban una atmósfera hostil a las Corporaciones provincialles, que aparecian como instituciones parasitarias de otras economías. Si la Diputación ha de ser un Organismo supermunicipal, que por su mayor capacitación y por contar con elementos técnicos más preparados que la inmensa mayoría de los Ayuntamientos, debe tutelar, proteger y fomentar el desenvolvimiento de los pequeños Municipios, mal puede aceptarse que en el orden económico viva, en gran parte, a expensas de los míseros necursos de esos Ayuntamientos, detrayendo de sus haciendas parte de los ingresos por solares, terrenos incultos y traviesas de frontones, y exigiéndoles el pago de una aportación forzosa que, por rebasar de las disponibilidades municipales, tenía que recaudarse, en muchos casos, por procedimientos ejecutivos.

En cuanto a las participaciones en tributos del Estado, el sistema era también inaceptable. Poco a poco y como consecuencia de la improcedencia de ciertos recursos, que fué preciso suprimir, tales como Cédulas personales y arbitros sobre la riqueza vitivinícola, el Estado venía comprometido a pagar a las Diputaciones cantidades fijas, o difícilmente revisables, compensatorias de la supresión de esos tributos, que se unían a las cifras que, por razones análogas, tenía ya de antiguo comprometidas por conceptos de Derechos reales, Timbre, Patente Nacional y otros semejantes. Lucían estas cifras en el Presupuesto del Estado, dando lugar a una inflación perjudicial, y obligaban a las Diputaciones a vivir a expensas del Erario, pendilentes de frecuentes y morosas liquildariones. De otra parte, siendo estas compensaciones, en su mayoría, de cuantía fija, no era factible su incremento 'en la proporción y con el ritmo que el acrecentamiento de los gastos exigía.

Por si fuera poco lo expuesto, una confusión total de recursos daba lugar a que las Diputaciones, participes de las Haciendas Municipales y estatal, resultasen, por otros conoeptos, tributarias a las 
mismas, teniendo que ceder a los Ayuntamientos parte de la compersación de Cédulas y que abonar al Estado múltiples contribuciones a impuestos.

Era, pures, obligado y pertinente transformar a fondo este régimen económico provincial, y creemos que la Ley de Bases promulgada ha conseguido esos fines con acierto y eficacia.

La separación de las Haciendas estatal, provinciales y municipales es completa en la nueva Ley. La exención de contribuciones por parte del Estado, general en su definición, sólo exige la puntualización de conceptos y casos imprescindibles en esta materia para la eficacia del benieficio y para evitar dudas, reclamaciones y litigios.

La supresión de las aportaciones forzosas municipales, aparte su acierto doctrinal, es un medio práctico de incrementar la economía de los Municipios, liberándolos de gastos elevados que les restaban medios para el cumplimiento de sus fines.

La supresión de las participaciones en tributos del Estado, justificadísima por las razones expuestas, no supone cicatería por parte de éste, pues el incremento que esta supresión representará para el Erario está en mucho excedido por la largueza con que el Gobierno, al aprobar la Ley, ha cedido a las Entidades locales y provinciales tributos y recargos, ha establecido reducciones de cuotas y exenciones tributarias $\mathrm{y}$ ha aceptado obligaciones que, hasta ahora, venian pesando sobre las Corporaciones. En resumen, podemos afirmar que la nueva Ley de Régimen Local significa para el Estado un sacrificio económico muy superior a los 500 millones de pesetas anuales.

Al intentar construir sobre bases sólidas un régimen de $\mathrm{Ha}$ ciendas Provinciales, había que comenzar por diestruir muchos de sus actuales pilares de sustentación. Esta destrucción previa, imprescindible para una reforma acertada y eficiente, aumentaba lógicamente la cifra del déficit y exigía un mayor esfuerzo para su nivelación y para obtener el incremento presupuestario que se reputaba imprescindible para el desahogado funcionamiento de las Diputaciones.

Seguramente el deseo de no agravar el problema, ha obligado a mantener los arbitrios ya establecidos sobre la riqueza radicante. 
Apuntamos anteriormente la improcedencia de estos arbitrios. Para comprender este criterio, bastará con meditar ligeramente sobre sus principales características. En primer lugar, carecen de toda base económica. $\mathrm{El}$ concepto radicante es suficientemente vago para que se pretenda ampliarlo a límites absurdos, dando lugar a que unas provincias graven artículos en cantidades de consideración, que en otras se encuentran libres, y como los gastos de producción son iguales en todas, $y$ en muchas ocasiones existe tasa en el precio de venta, resulta de notoria injusticia esa diferencia de tributos.

En los casos en que no exista precio de tasa, esa falta de equidad contributiva determina una competencia comercial que perjudica notablemente a los productores de la provincia en que se establece el arbitrio.

Finalmente, la mayoría de los productos gravados por el llamado arbitrio sobre la riqueza radicante, no se consumen en la provincia respectiva, y como su precio resulta recargado con el tributo, vienen de modo indirecto a levantar las cargas peculiares de una provincia los consumidores del artículo gravado de todo el resto de España.

No afecta a la justicia del tributo la mayor o menor cuantía de la recaudación, mas para que no se alegue como disculpa la insignificancia del arbitrio, conviene destacar que, aun cuando de ordinario se presenta como recargo de unos céntimos en el valor de la mercancía, el hecho de que actúe sobre unidades de peso o medida de reducidísimas proporciones, hace elevar el arbitiro de modo considerable. Baste comparar lo que representa, por ejemplo, cinco céntimos sobre el kilo de naranjas o de aceitunas que se producen en una finca, con la cuota que ese predio paga por contribución Rústica. Está, pues, plenamente justificado que la nueva Ley prohiba el establecimiento de estos arbitrios para el futuro, si bien, por razones fácilmente comprensibles, se permite la continuación de los que en la actualidad están autorizados.

Frente a la improcedencia técnica y práctica de los recursos que se suprimen, destaca la justicia, la ponderación y la productividad de los que se crean. Aparte el sistema indirecto de sanear las Haciendas provinciales suprimiendo tributos y contribuciones del Es- 
tado que gravan ias mismas, se les atribuyen, por modo directo, recargos del 20 por 100 sobre la contribución Rústica y del 40 por IOO sobre la contribución Industrial, ambas previamente reducidas al 80 y 75 por 100, repectivamente, de sus cuotas actuales.

Consideramos estos recargos procedentes por todos conceptos. Tienen, en primer término, una base firme de justicia, por constituir la aportación de una riqueza real de la provincia al levantamiento de las cargas de la misma. Se imponen con carácter general $y$, por tanto, con distribución equitativa del gravamen en toda la Nación. Dejan plenamente separadas las Haciendas provinciales de la del Estado. Permiten a las Diputaciones abrigar la esperanza fundada de que el aumento progresivo y natural de los gastos estará compensado con el incremento de la base tributaria. $Y$ constituyen, ađemás, un aliciente para la labor de la Diputación encaminada al progreso y fomento de la riqueza provincial, pues este aumento redundará en un mayor rendimiento de los recargos.

Prevé también la Ley, como ingreso de las Diputaciones, el excedente que resulte de los recursos previstos en la Base 22 para compensar a los Municipios la supresión del Repartimiento y de los arbitrios sobre productos de la tierra y sobre Pesas y Medidas. La forma de distribución de estos remanentes es la más justa y acertada, pues se atribuyen a las Diputaciones, en forma proporcional a la recaudación obtenida por los recargos, en las respectivas provincias. La previsión que, de otra parte hace la Ley, en orden a la necesidad de que los Ayuntamientos deban aplicar las demás exacciones autorizadas, antes de acogerse a la compensación referida, servirá, en primer término, para aumentar considerablemente la cuantía del excedente aludido y determinará, en ejercicios sucesivos, un incremento superior a medida que el desarrollo natural de las exacciones municipales permitan reducir la cifra destinada a remediar el posible déficit resultante en sus presupuestos a la implantación de la reforma.

Se incrementa también la economía provincial al ensanchar la esfera de su competencia y permitir la instalación de servicios, la realización de obras y la implantación de derechos y tasas sin el límite rel estricto coste del servicio. 
Parece que, con los recursos referidos, las Haciendas provinciales han de tener un desarrollo capaz de cubrir las necesidades de las Diputaciones, pero como las especialidades de cada provincia podrían deierminar, en algunos casos, resultados anormales y posiblemente déficits presupuestarios $o$, al menos, contracciones sensibles del incremento que se pretende obtener para sus cajas, se ha previsto un fondo de compensación y regularización de la reforma que se dota con un recargo del ro por Ioo de la contribución de Utilidades, Tarifa $3 \cdot^{\mathrm{a}}$, y con otro recargo sobre los denechos de Aduanas por la importación de café y té. Ambos recargos están plenamente justificados. El de Utilidades, porque viene a sustituir al actual arbitrio sobre el producto neto de las Sociedades y Compañías no gravadas en la Contribución Industrial. $\mathrm{Y}$ el segundo, porque deriva a un sector cuyos gravámenes actuales no han alcanzado el límite de presión tributaria correspondiente al alza obtenida por el precio de los productos en el mercado.

Un estudio basado en las Estadísticas oficiales de la Dirección general de Administración, y en las correspondientes al rendimiento de los tributos, contribuciones e impuestos que juegan en la reforma, nos permite abrigar la plena confianza de que ésta ha de ser para las Diputaciones solución plena y satisfactoria de sus necesidades y aspiraciones económicas. No debe existir sobre este extremo el menor temor después de conocer las afirmaciones categóricas y contundentes expuestas sobre el tema por el Ministro de la Gobernación en su magistral discurso de defensa del proyecto en las Cortes, pieza oratoria que por su exactitud, por su comprensión de los fundamentales problemas que aborda la Ley y por la claridad y robustez de sus razonamientos, bien pudiera servir como Exposición de Motivos de la misma.

Sólo como cálculo orientador, sin la pretensión de estudio económico de la reforma, nos permitimos aducir algunas cifras que proporcionarán un juicio aproximado sobre el resultado de la aplicación de la misma. 
Importe total de los Presupuestos provinciales según la Estadistica de

1943, última publicada..........................

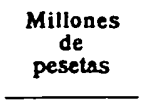

480

\section{Bajas de la Reforma}

Aportación forzosa municipal................... 84

Compensación de Cédulas personales............... 100

Otras participaciones en tributos del Estado............. 16

Recargos de solares, terrenos incultos y traviesas de frontones. 8

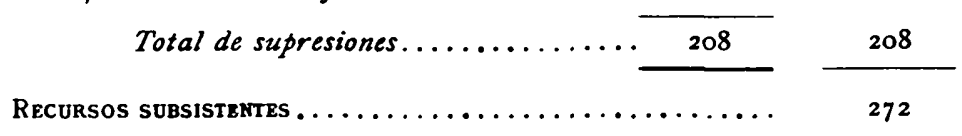

\section{Nuevos recursos}

Recargo de 20 por 100 de Rústica sobre la base del 80 por 100 de las cuotas...........................

Recargo del 40 por 100 de Industrial sobre la base del 75 por

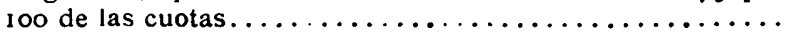

Excedente de los recargos destinados a compensar a los Ayun90 163 tamientos la supresión del Repartimiento, Productos de la tierra y Pesas y Medidas......................... 30

Desgravaciones de impuestos e incremento de Tasas y Contribuciones especiales...................... 20

Total de aumentos............ $\frac{303}{303} \frac{303}{575}$

Representan estos nuevos recunsos, por tanto, un aumento sobre las cifras presupuestarias actuales, de 95 millones de pesetas, y a ella debe unirse el rendimiento de los recursos destinados a remediar posibles déficits de alguna Diputación y a incrementar, de forma equitativa, los ingresos de las menos beneficiadas por la reforma. Estos tributos representan, según cálculos aceptables, la cantidard de 106 millones de pesetas, con lo que el montante de los presupuestos totales de las Diputaciones alcanzará la cantidad de 68r millones de pesetas, con un inçremento de 201 millones sobre las cifras actuales, o sea, un beneficio del 42 por roo de las disponibilidades actuales de las Corporaciones provinciales.

El problema, por tanto, de las Haciendas provincialles debe reputarse resuelto para un largo periodo de tiempo.

Fernando Camacho Baños. 